\title{
LIDERAZGO FEMENINO \\ Un análisis de las diferencias de género en la formación y desarrollo de asociaciones de inmigrantes africanos
}

\author{
FEMALE LEADERSHIP \\ An analysis of how gender-related differences influence training and \\ development in associations of African immigrants
}

Fidel MoLINA LUQUE molina@geosoc.udl.cat
Universidad de Lleida. España.

LUIS SAMPER RASERO Lluis.samper@geosoc.udl.cat

Universidad de Lleida. España.

Dolors MaYoral ARQUe dmayora@@geosoc.udl.cat

Universidad de Lleida. España.

\begin{abstract}
RESUMEN
En el presente estudio se describen, analizan y comparan las manifestaciones del liderazgo femenino en las asociaciones de inmigrantes africanos: sus objetivos de trabajo, temáticas y formas, organización e institucionalización. Para ello se analizan en profundidad diez historias de vida, partiendo de la hipótesis de la existencia de una clara diferenciación de objetivos entre las asociaciones de hombres y mujeres africanos derivados de la desigualdad básica de las posiciones sociales entre hombres y mujeres, y muy especialmente, de las culturas de género. Los resultados obtenidos sugieren que existen mujeres inmigrantes "fuertes" (ni sumisas ni ignorantes) con capacidad de liderazgo en la asociación, pero no por unas supuestas especificidades "femeninas" sino por un proceso de aprendizaje temprano (adolescente), éxito educativo y un origen social relativamente elevado que forjan una cierta rebeldía y la asunción de una autoridad explícita. De cualquier modo, no se observan diferencias relevantes entre el liderazgo femenino y el liderazgo masculino, ya que en ambos casos se da un cierto "carisma", la existencia de unas dotes personales que se desarrollan desde la interacción en situaciones sociales concretas.
\end{abstract}

Palabras Clave

Asociacionismo; Conflicto; Género; Inmigración; Liderazgo; Socialización; Sociología de la Educación Intercultural.

\section{Abstract}

This study describes, analyses and compares manifestations of female leadership in associations of African immigrants, examining such factors as work objectives, themes and forms, organisation and institutionalisation. It was based on an in-depth analysis of ten life histories, starting from the hypothesis that there is a clearly gender-based difference between the objectives of African associations comprised of men and of women and that this difference stems from the basic inequality of the respective social statuses of men and women and, more specifically, from gender-related culture. The results obtained suggest the existence of "strong" (neither submissive nor ignorant) female immigrants with the capacity to lead associations, but whose character is not the result of any supposedly specifically "feminine" characteristics, but rather to a process of early (adolescent) learning, academic success and relatively high social origin, all of which help 
to forge a certain rebellious streak and to lead certain women to assume positions of authority. Whatever the case, it was not possible to observe any relevant differences between female and male leadership; both tend to be characterised by a certain "charisma" and the presence of personal qualities that were the result of interactions within specific social contexts.

KEYWORDS

Associations; Conflict; Gender; Immigration; Leadership; Socialization; Sociology of Intercultural Education.

\section{JUSTIFICACIÓN TEÓRICA}

Durante siglos las mujeres han sido heterodesignadas por los poderes usualmente masculinos. Los tópicos sobre lo femenino (sus características, en especial su supuesta alteridad frente a la identidad androcéntrica) esconden y legitiman la dominación política, la explotación económica y la subordinación cultural y sexual. Si además se trata de mujeres africanas e inmigrantes el riesgo de sucumbir al estereotipo negativo es, si cabe, aún mayor. Pero los movimientos asociativos ofrecen ejemplos de prácticas y discursos que contradicen estos prejuicios, ya existentes, sexistas y etnicistas.

Desde una perspectiva teórica, las preguntas fundamentales son: ¿cómo articular los enfoques psicologistas y sociologistas del liderazgo? Más concretamente ¿cómo se aprende a ser dirigente en las asociaciones de inmigrantes? ¿Cuál es el peso relativo de las características personales supuestamente innatas; por ejemplo, el carisma, respecto a las variables situacionales y organizativas?

En este sentido, como hipótesis de trabajo, constatamos que ha transcurrido más de medio siglo desde que Simone de Beauvoir denunciara la alteridad femenina $y$, pese a los evidentes avances en los ámbitos jurídicos, educativos y laborales, no es menos cierto que subsisten importantes desigualdades de género $y$, muy especialmente, los estereotipos y prejuicios hacia las mujeres. Estas percepciones y representaciones de la mujer como "el otro": es decir como oposición e incluso inversión de la excelencia humana, son significativamente dirigidas hacia los colectivos femeninos más inferiorizados, como por ejemplo, las mujeres inmigrantes africanas. En todo caso, cada vez más, van apareciendo estudios rigurosos sobre género, que son aportaciones al debate teórico internacional desde las voces de las "otras mujeres" (Puigvert y Muñoz 2012). En este sentido, y frente a las imágenes sociales de pasividad, inercia, debilidad, menguada racionalidad... lo cierto es que la mera existencia de asociaciones de mujeres inmigrantes también cuestiona estos tópicos. ¿Cuáles son las funciones de tales asociaciones respecto a la erosión 0 perpetuación de las desigualdades de género? ¿Quiénes son y cómo actúan las personas que han generado estas organizaciones? ¿Existen diferencias entre el liderazgo asociativo masculino y femenino? ¿Cómo han accedido a las funciones, la institucionalización y dirección de las asociaciones? ¿Cuál es el peso relativo de las variables situacionales respecto a las biográficas en el proceso de consolidación del liderazgo? 


\section{Objetivos}

En esta línea, tres objetivos parecen pertinentes:

- Revisar conceptualmente el tema del liderazgo asociativo con especial énfasis en las controversias sobre el liderazgo femenino.

- Presentar una visión de conjunto del asociacionismo femenino respecto del masculino en la muestra de organizaciones de inmigrantes africanas procedentes de diferentes comunidades autónomas.

- Estudiar en profundidad diez perfiles biográficos procedentes de la muestra anterior centrándonos en el análisis comparativo de los diferentes estilos de liderazgo y en los procesos que contribuyen a la emergencia de sus funciones.

Por consiguiente, la estructura del artículo consta de una revisión bibliográfica del tema en la que analizamos la contribución de autores clásicos,así como las aportaciones de estudios recientes, y dos apartados de contenido predominantemente empírico.

En el primero, y a partir de una metodología cuantitativa, se revisan 206 cuestionarios de asociaciones de inmigrantes africanos ubicadas en cuatro comunidades autónomas del Estado español: Cataluña, Comunidad Valenciana, Navarra y La Rioja. Se han analizado atendiendo a su evolución así como a sus actividades, finalidades, tamaño, composición étnica o nacional... desde la perspectiva de las diferencias de género.

En un segundo apartado, empírico, se describen e interpretan desde una perspectiva cualitativa los trayectos biográficos de seis mujeres y cuatro hombres que, a partir de una previa selección de la muestra total, reflejan tanto el desarrollo del liderazgo asociativo como los estilos de conducción y dinamización de tales instituciones. Finalmente, hemos elaborado unas conclusiones que sintetizan los resultados obtenidos y las cuestiones pendientes de resolución.

\section{Dimensiones y ÁmBitos del LIDERAZgo. LA CONTROVERSIA SOBRE EL LIDERAZGO FEMENINO}

Tal vez porque vivimos en tiempos de sobresaltos económicos aparejados a una continuada desorientación ideológica lo cierto es que el liderazgo es un término que está de moda. Su uso y abuso en los más variados ámbitos de la vida cotidiana (la política, el deporte, la actividad empresarial...) esconden, no obstante, una amplitud de significados diversos e incluso, en ocasiones, contradictorios. Por ejemplo, se utiliza el término para referirse al carisma de un entrenador de fútbol pero también como sinónimo de capacidad e influencia política de un estado nacional concreto o como mero equivalente de la preeminencia jerárquica en un grupo o en una organización. Estamos ante un fenómeno social poliédrico en el que confluyen lo psicológico y lo social, la subjetividad personal y la objetividad del contexto organizativo y estructural, los rasgos idiosincráticos de los 
agentes sociales pero también las específicas circunstancias históricas de cada época, y cuyo estudio demanda, en ocasiones, la metodología experimental de los microgrupos de laboratorio, pero también estudios etnográficos sobre los grupos y las organizaciones sociales específicas.

\section{Perspectivas psicosociológicas}

Desde una perspectiva psicosociológica el liderazgo es solo una faceta, aun cuando la más fácilmente visible, de un largo proceso de diferenciación de roles en el seno de la dinámica grupal. El liderazgo es simplemente este concepto aplicado a la situación adquirida en un grupo cuando la diferenciación de roles resulta total o parcialmente de la interacción, influyendo las acciones de otros en un acercamiento compartido hacia los objetivos comunes o compatibles (Gibb 1969: 270; Peters 2005). Como ya admitiera Homans ([1950] 1963) esta aproximación a las normas y objetivos compartidos y valorados por el grupo implica tanto una centralización de la interacción como un mayor rango grupal. Cuanto más elevada sea la posición en la pirámide interactiva mayores son las facilidades para acceder a la información y, por tanto, para controlar el grupo. De este modo todos estos elementos se relacionan entre sí, y al reforzarse mutuamente integran el liderazgo (Homans 1963: 212). En otras palabras, el liderazgo implica una serie de roles (facilitación de objetivos, cumplimiento de las normas, centralización interactiva, control social, canalización de la información...) que desempeñados por una 0 varias personas contribuyen al éxito de la demanda grupal.

Por otra parte, al igual que cualquier otro comportamiento de roles, el liderazgo es tanto una función de atributos personales (las capacidades, aptitudes e historial del líder) como del sistema social concreto en que se desarrolla la interacción. No obstante, diferentes estudios realizados por grupos experimentales así como sobre organizaciones reales concluyeron ya a finales de los años cuarenta del pasado siglo (Stogdill 1948, citado por Fiedler [1971: 916]) que no existen rasgos específicos de la personalidad del líder sino que la capacidad predictiva de tales características psicológicas (inteligencia, autoconfianza, sociabilidad...) dependen de cada situación concreta aunque, como veremos más adelante, esta orientación psicologicista no ha desaparecido totalmente, la teoría e investigación en la psicología social del liderazgo se ha centrado en tres grandes modelos:

a) Teoría de la contingencia: Fiedler (1971), a partir de la distinción de Bales (1950) entre líderes especializados en la relación social versus líderes especializados en las tareas (también Blake y Mouton 1964), elaboró una escala CPUL (descripción del compañero de trabajo preferido en último lugar) que permite medir el grado en que un individuo del grupo está motivado por la relación social o por el trabajo y la productividad. La investigación en grupos primarios experimentales, así como en organizaciones concretas (escuelas, empresas, ejército...), indica que la emergencia y el éxito de uno u otro tipo de liderazgo dependen tanto de la estructura favorable o desfavorable de la tarea a realizar como de la posición de poder (fuerte o débil) del líder. 
b) Teoría transaccional: prosigue la crítica de los modelos personalistas pero aún es más situacionista que el modelo de la contingencia. Desde esta perspectiva se subraya la interdependencia entre el líder y los seguidores. Concretamente, Hollander y Julian (1971) observan que:

- El liderazgo constituye básicamente una relación de influencia recíproca entre personas que dependen de otras para la realización de ciertas metas comunes.

- Dicha relación se establece con el tiempo e implica un intercambio o transacción.

- Existen funciones o tareas diferenciales que se consideran propias del líder.

- Se puede y se debe estudiar la eficacia de un liderazgo respecto a la obtención de los efectos deseados por el grupo.

Bass (1985) contrapone este modelo con el llamado transformacional; se trata de conseguir cambiar la escala de valores, actitudes y creencias obteniendo un rendimiento mayor al esperado. Este estilo de liderazgo deriva hacia el carisma entendido como un modelo en el que se dan cualidades personales extraordinarias.

c) Teorías de la identidad social (Haslam 2004): Partiendo de un enfoque más sociocognitivo consideran que la esencia del liderazgo no es tanto la personalidad del líder 0 las funciones que desempeña como las atribuciones o estereotipos que los seguidores construyen hacia las personas que consiguen que el grupo alcance sus objetivos. En este sentido, la tarea del liderazgo es la génesis y el desarrollo de una identidad grupal satisfactoria. Dicho de otro modo: la influencia del líder deriva de su habilidad para crear e incorporar un positivo y distintivo sentido del "quiénes somos".

\section{Perspectivas sociológicas: sociedades versus organizaciones}

Por otra parte, desde un enfoque propiamente sociológico, liderazgo significa poder sobre otras personas. El tema clave de dicha relación es la capacidad de un actor social para que prevalezca su voluntad frente, o incluso, contra la resistencia de otros individuos. Aquí lo pertinente es remitirnos a la conocida tipología weberiana de dominación legítima: legal, tradicional y carismática (Weber [1922] 1984). Según el influyente sociólogo alemán, esta última, la dominación carismática, es una relación social específicamente extraordinaria y puramente personal (Weber 1984:714). Se fundamenta en la devoción afectiva hacia una persona y a sus dotes sobrenaturales o "carisma". Dichas facultades extraordinarias, no obstante, pueden ser diversas (heroísmo, poder intelectual, oratoria, dotes mágicas, revelaciones...) según se trate de un profeta, un héroe guerrero 0 un demagogo (Weber 1984:711). Dicho de otro modo, y anticipando las investigaciones psicosociológicas anteriormente citadas: no existiría un modelo universal de liderazgo. Para Giddens (1989: 641) el liderazgo constituye una importante dimensión del cambio social. Ahora bien, para que un individuo concreto pueda alcanzar posiciones de lide- 
razgo y pueda llegar a ser socialmente influyente es menester que previamente existan unas condiciones sociales favorables. Son los contextos sociales específicos los que favorecen o dificultan que unas determinadas personas (Julio Cesar, Newton, Hitler...) acaben convirtiéndose en figura histórica. De hecho, la investigación sociológica indica que según cambian las circunstancias sociales, económicas o culturales análogamente varía el perfil de liderazgo en una asociación ${ }^{1}$.

Uno de los problemas que suscita la utilización del concepto de liderazgo es justamente si este es igualmente válido según sea el escenario en el que se desarrolla la acción social: grupos primarios, organizaciones, comunidades o sociedades complejas; por no hablar del fenómeno de las redes sociales, plenamente actual. La cuestión es ¿son igualmente generalizables los resultados, en general bastante concluyentes, de los estudios sobre pequeños grupos a los otros escenarios?

Un reciente estudio sobre el liderazgo social entre representantes significados de la sociedad civil catalana (Cantó, Castiñeira y Font 2009) nos llevan a destacar la importancia del aprendizaje del liderazgo; esto es, los itinerarios biográficos que llevan algunas personas a convertirse en catalizadores del cambio social. Frente a los enfoques psicológicos personalistas o psicosociológicos situacionistas, los autores presentan un modelo empírico-teórico en el que a partir de unos factores desencadenantes personales (reflexividad, concienciación, búsqueda de sentido, necesidad de afiliación...) y contextuales (incidentes críticos, influencias y referentes, experiencias transformadoras), y previo un proceso de decisión, se adquiere un compromiso cívico que conduce finalmente al liderazgo social. A partir de una explotación exhaustiva de las historias de vida, se han situado en un mismo momento vital, la etapa decisiva, un salto existencial y el proceso de despertar de la conciencia cívica: la adolescencia y la primera juventud. Pero dada la composición demográfica de los sujetos, también aquí coinciden elementos de ciclo vital (la construcción de la identidad personal) con los propiamente contextuales o generacionales (el período final del franquismo y la transición democrática).

Por otra parte, las investigaciones recientes centradas en las organizaciones sociales, especialmente, las focalizadas en el ámbito empresarial, han actualizado la importancia de los factores personales del liderazgo. Así, Bass (1998), frente al clásico liderazgo transaccional, utiliza los inevitables conflictos y crisis para ampliar la conciencia de los seguidores y ofrecerles apoyo, orientación y experiencias de desarrollo. También dentro de este enfoque neo-carismático, Gardner (2011) atribuye seis características comunes a todos los líderes: a) el hecho de tener una historia o un mensaje central, b) disponer de un auditorio dispuesto a oírla y preparado para reaccionar, c) disponer de algún tipo

\footnotetext{
${ }^{1}$ Un estudio sobre asociaciones de inmigrantes pakistaníes en Gran Bretaña (Joly 1987: 68 y ss.) indica un cambio en el perfil social entre los "viejos" y "nuevos" líderes. Para los primeros con predominio de relaciones clientelares, la identidad islámica y la reproducción de la cultura original eran criterios básicos, mientras que en la segunda generación, los dirigentes asociativos se caracterizaban por un buen nivel de estudios y una decantación ideológica hacia el partido laborista.
} 
de base institucional, d) debe encarnar algún tipo de historia, e) la mayoría de líderes creativos ejercen su influencia indirectamente a través de los productos simbólicos que crean; líderes directos (con pericia) y líderes indirectos (no pueden alcanzar conocimientos precisos).

A partir de la diferenciación entre poder duro (capacidad de organizar y aptitudes maquiavélicas) y poder blando ( $\mathrm{Cl}$ emocional, dotes comunicativas y capacidad para ofrecer una visión alternativa de la realidad), Nye ha elaborado una tipología del liderazgo. Según este autor, los cambios sociales derivados de la globalización, así como de la democratización y revolución de la información, están originando una transformación en el contexto de las organizaciones posmodernas, a lo largo de un continuo que va de un estilo directivo basado en el mando a otro basado en la influencia. No obstante, el contexto determina cuando es más conveniente utilizar el poder duro (liderazgo transaccional) o el blando (liderazgo inspirador). La capacidad para combinar el poder blando de una estrategia que entiende la evolución del contorno, aprovecha las tendencias y se adapta tanto al contexto como a las necesidades de los seguidores, es lo que denomina poder inteligente (Nye 2011: 96).

\section{Liderazgo asociativo y género}

Una pregunta especialmente pertinente que nos hemos planteado en nuestro propio análisis sobre el liderazgo en las asociaciones —dados los estereotipos hacia las mujeres africanas- es si cabe diferenciar entre liderazgo masculino y liderazgo femenino (Eagly y Carli 2003).

Un estudio sobre asociaciones indígenas ecuatorianas (Martínez 2011) indica la emergencia de una forma de liderazgo específicamente femenino basado en cinco elementos comunes:

1. Precocidad en el trabajo comunitario.

2. Relación con el prestigio político de la familia de origen.

3. Bilingüismo (castellano y lengua propia) y adecuado nivel de escolarización.

4. Revalorización de la cultura indígena.

5. Discurso organizativo en el que lo étnico prima sobre las dimensiones de género.

La conclusión es que estas mujeres han construido su capacidad de liderar las asociaciones indígenas superando los escollos de sus nuevos roles femeninos (sobrecarga de actividades y estereotipos de designación social) utilizando a su favor los cambios sociales generados por la migración. Frente al tópico tradicional de "mujeres enmudecidas" han sabido desarrollar formas de capacidad discursiva que les han otorgado legitimidad:

- como eficaces movilizadoras de recursos

- $\quad$ mediando en los conflictos organizativos

- $\quad$ activando sus redes familiares de grupos con prestigio social. 
En este ejemplo, el éxito del liderazgo femenino obedece más a un proceso de aprendizaje social bajo específicas condiciones de cambio social que a unas supuestas dotes "naturales" femeninas. Es más, el liderazgo fue conquistado al ejercer lo que tradicionalmente había sido un atributo exclusivamente masculino: la competencia lingüística en el espacio público.

No obstante, para otras autoras, por ejemplo Fisher (2000: 15) en el contexto actual de erosión del patriarcado, cabe reivindicar una serie de "capacidades innatas" femeninas (habilidad verbal, empatía, impulso maternal, preferencia para cooperar...) que facilitarían un nuevo modelo de liderazgo. Estos nuevos estilos de gestión no solo ayudarían a conciliar trabajo y familia sino que serían especialmente productivas en un contexto organizativo postfordista: más flexible y abierto con desarrollo de culturas colaborativas", mayor movilidad, énfasis en las redes sociales y las tecnologías de la información y la comunicación (TIC).

En esta línea, algunas autoras como Chinchilla (2004: 111) preconizan un modelo de organización empresarial más humano basado en un estilo de liderazgo que conjugue racionalidad y afectividad, entre otros requisitos. Frente a la tendencia masculina a contemplar el mundo de un modo impersonal, basándose en criterios lógicos y legales, las mujeres directivas equilibrarían esta visión con dosis de intuición, de modo que el resultado final sería una empresa más humana, más amable, más flexible y más eficiente ${ }^{2}$.

Esta propuesta a favor de un liderazgo femenino o "postheroico" parece coincidir con las teorías, anteriormente expuestas favorables a un cambio de tendencia en el liderazgo organizativo según las cuales se estaría produciendo una sustitución de poder duro por el poder blando. No obstante, J. S. Nye (2011: 63-65) arguye que la equiparación entre liderazgo femenino y poder blando es una identificación arriesgada en la medida en que los estereotipos de género, aunque sean positivos, pueden resultar peligrosos para las mujeres, los hombres y el liderazgo eficaz en general. En otras palabras, este cambio de estilo de liderazgo afecta tanto a hombres como a mujeres; $y$ todos deben adaptarse a él. Investigaciones recientes (Barberá, Sarrió y Ramos 2000) concluyen: 1. que los varones y las mujeres no parecen diferir de modo significativo en su mayor o menor eficacia como directivos, ni tampoco en el nivel de compromiso personal con su trabajo; 2. en relación a las pequeñas diferencias observadas en dimensiones parciales del comportamiento se obtienen resultados favorables para los varones en la dirección orientada a la tarea y para las mujeres respecto del liderazgo interpersonal. 3. las diferencias intersexuales cuando aparecen pueden explicarse desde factores contextuales no vinculados con el hecho de ser mujer o varón. Los resultados sobre el nivel de compromiso personal con el trabajo se vinculan con factores de tipo personal (edad, nivel de formación, carácter) y muy especialmente, con responsabilidades familiares (vivir solo o en pareja, hijos o no

\footnotetext{
${ }^{2}$ Un estudio de Bass y Avolio (1994) demostró que, efectivamente, las mujeres directivas eran percibidas por sus subordinados como más cercanas al modelo, operacionalizado a través del cuestionario MLQ, de líder transformacional.
} 
hijos...). Incluso, según las autoras, en algunos casos el resultado parece depender del método de análisis y de la prueba realizada. Estas autoras observan contradicciones entre los resultados obtenidos en la aplicación de MLQ y el metaanálisis resultado de los grupos de discusión, por lo que deducen que las diferencias en el estilo de dirigir no dependen del sexo sino de las características personales o del estilo de la organización; a la vez que ponen de manifiesto que cuando los resultados obtenidos se interpretan en abstracto emergen con facilidad los estereotipos de género.

En esta línea, en las investigaciones que se desarrollaron en la década de los noventa por Bass y Avolio (1990; 1994) se observan cómo los resultados pueden relacionarse con los valores de hombres y mujeres, dado que solamente obtuvieron diferencias estadísticamente significativas en variables como la consideración individualizada, la influencia idealizada (carisma) o en los factores de dirección; mientras que las mujeres obtuvieron puntuaciones superiores en las escalas de esfuerzo extra, eficacia, satisfacción y recompensa contingente. Druksat (1994) introdujo a finales del siglo pasado la importancia del carácter tradicional o no tradicional de la organización como variable clave a la hora de estudiar el papel del género en el liderazgo. Ramos, Sarrió y Candela (2002) consideran que las nuevas organizaciones demandan un comportamiento directivo distinto al tradicional más basado en el estilo transformacional, pasando de organizaciones jerarquizadas y rígidas a organizaciones horizontales más flexibles con mayor capacidad de adaptarse a los cambios en el mundo laboral. Son concretamente estos factores los que demandan nuevas habilidades de liderazgo como la capacidad de trabajar en equipo, la creatividad, toma de decisiones y dominio de las técnicas de comunicación.

\section{GÉNERO Y ASOCIACIONES DE INMIGRANTES}

\section{Metodología de investigación}

En una primera fase de la investigación, después de haber realizado un análisis de los casos existentes sobre el volumen y la evolución de la inmigración de origen africano en Cataluña, Comunidad Valenciana, La Rioja y Navarra, se diseñó un breve cuestionario dirigido a representantes de asociaciones que nos permitieran definir su perfil: denominación, año de creación, estructura organizativa, número de asociados, actividades que organizan, ámbito territorial, coordinaciones y colaboraciones existentes que nos facilitaran construir una tipología a través de los análisis multivariados. El trabajo empírico se realizó simultáneamente en las cuatro comunidades autónomas.

Sobre un total censal de más de 300 asociaciones se obtuvieron 206 cuestionarios realizados a los representantes de las asociaciones distribuidos según comunidades: 138 correspondían a Cataluña, 54 a la Comunidad Valenciana y 15 a La Rioja-Navarra. Del conjunto, el $61,6 \%$ tenían una antigüedad igual o inferior a ocho años y la mayoría $(78,6 \%)$ eran predominante 0 exclusivamente masculinas. Más concretamente: 
Cuadro 1.

Asociaciones según género.

\begin{tabular}{|c|c|}
\hline Solo hombres & 15 \\
\hline Principalmente hombres & 147 \\
\hline Mixta & 18 \\
\hline Principalmente mujeres & 11 \\
\hline Solo mujeres & 10 \\
\hline
\end{tabular}

Fuente: Elaboración propia.

Se utilizó la técnica de barrido, es decir, puesto que no todas las asociaciones están registradas y se pretende encuestar a todas las posibles, igualando muestra a población, se detectaron las que no están a través de las instituciones comarcales, locales u otras entidades que trabajan con y para la inmigración; esto explica la diferencia entre el número de cuestionarios obtenido y el número de asociaciones con las que finalmente se trabajó.

\section{Visión de conjunto y evolución de las asociaciones}

Una primera observación que se desprende del cuadro anterior es que el asociacionismo de mujeres es minoritario y reciente, tal y como se puede comprobar a partir del tiempo de creación de la asociación; aunque existen diferencias internas, tal y como se ilustra en la tabla posterior:

Más allá de estos datos, su distribución presenta una notable dispersión e irregularidad a excepción de las asociaciones 'principalmente hombres' cuya constitución ha sido más continua en el tiempo. Probablemente, la diferencia más notable, en cuanto al tiempo de creación sea el de las asociaciones de 'solo mujeres' cuyo origen se concentra en un elevado porcentaje en los últimos tres años.

\section{Cuadro 2.}

Asociaciones según año de creación.

\begin{tabular}{|c|c|}
\hline Solo hombres (15) & A partir del 2003 se crea el $66,6 \%$ \\
\hline Principalmente hombres (147) & A partir del 2003 se crea el $40,9 \%$ de asociaciones \\
\hline Mixta (18) & A partir de 2003 se crea el $50,1 \%$ \\
\hline Principalmente mujeres (11) & A partir de 2003 se crea el $54,6 \%$ \\
\hline Solo mujeres (10) & A partir de 2003 se crea el $70 \%$ \\
\hline
\end{tabular}

Fuente: Elaboración propia. 
En relación al desarrollo de responsabilidades en la asociación, la mayoría de hombres y mujeres entrevistados tienen una experiencia de cinco o menos años, particularmente, el grupo de asociaciones de "principalmente mujeres" se concentra en los últimos tres años

Cuadro 3.

Años de responsabilidades en la asociación

\begin{tabular}{cccccc}
\hline Años & Solo hombres & Principalmente hombres & Mixtas & Principalmente mujeres & Solo mujeres \\
\hline 1 & $80,0+$ & $44,2-$ & 38,9 & 72,7 & 60,0 \\
2 & $6,7-$ & $46,9+$ & 50,0 & 18,2 & 20,0 \\
3 & 13,3 & 3,4 & 5,6 & - & 10,0 \\
4 & - & 5,4 & 5,6 & 9,1 & 10,0 \\
\hline
\end{tabular}

Fuente: Elaboración propia.

Además, el $80 \%$ del grupo 'principalmente mujeres' y el $70 \%$ del de 'solo mujeres' afirman no haber participado anteriormente en asociaciones en su país de origen; aunque, no obstante, algunas de ellas habían tenido contactos con anterioridad.

Contrariamente a lo que sucede en las asociaciones de 'principalmente hombres', en relación a su tamaño, en ningún caso superan los cien afiliados/as; además, las altas son poco frecuentes mientras que las bajas lo son algo más. Las franjas de edad de las afiliadas se sitúan entre los 25 y 45 años, principalmente de origen marroquí, tunecino y de Guinea Ecuatorial.

\section{Desarrollo de las asociaciones y de sus actividades}

Aparte de la formación en lengua (catalana, española, euskera, valenciana) las principales actividades que realizan quedan reflejadas en la tabla posterior. En relación a las comisiones en las que participan, destaca el interés por la comisión de cultura en todos los grupos de asociaciones, seguida por la de educación, comunicación y deportes. No se hallan diferencias sustantivas en cuanto a intereses entre las asociaciones de o con predominio de mujeres, a excepción de la de mediación intercultural.

En lo que se refiere a las actividades en las que participan destaca para el grupo de 'principalmente hombres' la de sensibilización con un $35,4 \%{ }^{*}$ estableciéndose una relación estadísticamente significativa entre este grupo y esta actividad, también en proyectos de inserción laboral con un $30,6 \%{ }^{*}$ siendo estadísticamente significativo. También, en este mismo grupo, los proyectos de mediación alcanzan el $42,2 \%$. Asimismo se interesan por las actividades de formación en lengua española. Las asociaciones de 'principalmente mujeres' también trabajan en proyectos de mediación (30\%) y las de 'solo mujeres' ofrecen clases en lengua de origen. En las asociaciones 'mixtas' y de 
Cuadro 4.

Asociaciones según actividades.

\begin{tabular}{lccccc}
\hline & $\begin{array}{c}\text { Solo } \\
\text { hombres }\end{array}$ & $\begin{array}{c}\text { Principalmente } \\
\text { hombres }\end{array}$ & Mixta & $\begin{array}{c}\text { Principalmente } \\
\text { mujeres }\end{array}$ & Solo mujeres \\
\hline Clases de religión & 13,3 & 8,8 & - & 9,1 & 10,0 \\
Sensibilización externa & 13,3 & $35,4+$ & 22,2 & 27,3 & 20,0 \\
Proyectos de mediación & 33,3 & 42,2 & 44,4 & 63,6 & 30,0 \\
Proyectos de inserción laboral & 6,7 & $30,6+$ & 27,8 & 18,2 & 10,0 \\
Proyectos de codesarrollo & - & 10,9 & - & 9,1 & 10,0 \\
Acogida & - & 0,7 & - & - & 10,0 \\
Acc. Mujeres inmigrantes & 6,7 & 0,7 & 5,6 & - & 10,0 \\
Ayuda países de origen & - & 2,7 & - & 9,1 & - \\
Ayuda económica a inmigrantes & - & 2,0 & - & - & \\
necesitados & - & 2,7 & - & - & - \\
Asesoramiento legal & 13,3 & 11,6 & 16,7 & - & 20,0 \\
Clases en lengua de origen & 26,7 & 8,2 & 16,7 & 18,2 & - \\
Clases en cultura de origen & - & 4,8 & - & - & - \\
Cursos de informática & - & 6,8 & 22,2 & 9,1 & 20,0 \\
Otros cursos & 6,7 & 2,0 & - & - & - \\
Clases formación adultos & - & 11,6 & - & 9,1 & 10,0 \\
Fiestas & 13,3 & 2,0 & - & - & 10,0 \\
Actividades deportivas & 26,7 & 21,1 & 33,3 & 18,2 & 20,0 \\
Otras & 6,7 & 2,0 & - & 9,1 & - \\
Ns/nc & & & & & \\
\hline Fun & & & & & \\
\hline
\end{tabular}

Fuente: Elaboración propia.

'principalmente mujeres' desarrollan las mismas actividades pero en un orden inverso en relación con el anterior; es decir, proyectos de mediación, inserción laboral y sensibilización externa. El resto de actividades, a excepción de las clases de lengua de origen, obtienen porcentajes escasamente relevantes.

Estas dos variables: participación en comisiones y participación en actividades, ponen de relieve la escasa o nula relevancia de las diferencias de comportamiento y de intereses entre hombres y mujeres en relación a las asociaciones de inmigrantes.

En referencia al conocimiento de lenguas (incluida el valenciano) los porcentajes no son significativos. En cuanto a las creencias religiosas resulta estadísticamente significativa la relación entre asociaciones 'principalmente de hombres' y ser musulmán en un $80,3 \%^{*}$ (de un total de 44 individuos).

El tiempo de afiliación es estadísticamente significativo en un $66,7 \%{ }^{*}$ para las asociaciones masculinas con un tiempo inferior a cinco años; mientras que, en las de 'principalmente hombres' el $51,0 \%{ }^{*}$ se sitúa entre los cinco y diez años. Para el grupo de 'principalmente mujeres' el 63,6\% tiene menos de cinco años de afiliación. De manera 
similar, el grupo de asociaciones de 'solo mujeres' se sitúan mayoritariamente en el período de menos de cinco años de afiliación; es decir, son de reciente creación.

En relación a los entrevistados, el $55,5 \%$ es el presidente, el 19,4\% el secretario, y el $8,7 \%$ el fundador de la asociación, el resto de posiciones son inferiores al $5 \%$ del total de la muestra. Asimismo, el $66,1 \%$ es originario del norte de África obteniendo una relación estadísticamente significativa entre ambas variables. En referencia a los años de permanencia en el cargo, el 55,7\% llevan entre uno y seis años mientras que el $26,2 \%$ llevan entre 7 y 10 años. Para el grupo de 'solo mujeres' (10 en total) el 66,7\% ha sido presidenta y el 33,3\% secretaria, principalmente, en asociaciones de tipo cultural; ello, no obstante, debe considerarse, dada su reciente creación, su escaso número de afiliados, así como su permanencia, que no podamos establecer conclusiones de interés. Sí que existen coincidencias entre las edades de los afiliados y afiliadas que se sitúan en el intervalo de entre los 25 y los 45 años; asimismo, se observa una cierta coincidencia entre ciertas comunidades de origen de hombres y mujeres y una mayor propensión a la asociación. La procedencia de las afiliadas se centra principalmente en el norte de África: Marruecos, Túnez y, excepcionalmente, Guinea Ecuatorial.

En relación a si previamente existía una red informal o contactos informales el 27,3\% de las asociaciones de 'principalmente de mujeres' y el 50\% de las de 'solo mujeres' habían mantenido algunos con anterioridad.

Otros datos de interés: todas las asociaciones coinciden en la realización de una media de 2 a 3 asambleas al año, se reúnen en locales cedidos, de los que se sienten bastante satisfechos. Fundamentalmente, viven de las aportaciones de los asociados y, en caso de recibir subvenciones, proceden de los ayuntamientos. Asimismo mantienen relaciones de colaboración con la administración, con fundaciones, entidades que trabajan con inmigrantes, con otras asociaciones de inmigrantes y con las instituciones del país de origen. Solo una tercera parte pertenecen a plataformas o foros.

En lo que se refiere a la utilidad de las redes, tanto hombres como mujeres son más bien escépticos, especialmente en el $70 \%$ de las de 'solo mujeres' y en el $54,5 \%$ de las de 'principalmente mujeres'.

\section{Perfiles biográficos. El camino hacia el liderazgo}

\section{Justificación de la selección de la muestra}

Del conjunto de asociaciones de la investigación, se han seleccionado 10 casos a partir de un doble criterio individual sobre el liderazgo y un criterio colectivo de organización. En esta línea, se han seleccionado asociaciones "de" inmigrantes y no asociaciones "para" inmigrantes, ya que uno de los aspectos fundamentales de la metodología cualitativa es dar la voz a los protagonistas, en un sentido dialógico comunicativo, y esta orientación se muestra clave para nuestro objetivo de investigación. En este sentido también, uno de los criterios de carácter más individual se centra precisamente en que la persona 
entrevistada sea de origen extranjero, independientemente de que posea actualmente 0 no la nacionalidad española. El segundo y último criterio individual ha sido que no solo sea un jefe o cargo directivo formal (headship) como presidente/a, tesorero/a o miembro de la junta directiva, sino que ejerza funciones manifiestas de liderazgo (leadership), reflejando una cierta personalidad carismática, atractiva para sus seguidores.

De todas maneras, las limitaciones metodológicas de los estudios de caso (como en el conjunto de la metodología cualitativa) están a la orden del día en relación con la posible "objetividad" del enfoque y la imposibilidad de extrapolar a la población en general porcentajes estadísticos, por ejemplo. En todo caso, también se deben destacar las ventajas de esta misma metodología cualitativa a la hora de profundizar en todos los posibles discursos (mayoritarios y minoritarios) pertinentes en relación con la temática estudiada, así como de las percepciones, sentimientos y emociones que difícilmente podrían aflorar a través de una metodología cuantitativa (Szepanski 1978; Pujadas 1992; Ruiz Olabuénaga 2003).

\section{El proceso de aprendizaje del liderazgo}

Como ya se ha indicado en el apartado segundo, aunque se puedan tener ciertas predisposiciones casi "innatas", lo cierto es que el líder "se hace" más que "nace". En este sentido podemos hablar de un proceso hacia la formación del líder, un camino hacia el liderazgo. Este camino no está exento de cuestiones individuales y grupales, de interacciones: seguramente lo más acertado sería concluir que es fruto de las interrelaciones y experiencias personales y colectivas.

Todo ello queda reflejado a lo largo de las historias de vida y entrevistas llevadas a cabo con unos informantes que son claramente líderes de asociaciones y organizaciones, y que han tenido que abrirse camino en un contexto difícil y complejo.

En un primer momento, podemos detectar que, realmente, se da una selección de los mejores, de los más preparados, que tienen ciertas aptitudes (y actitudes) que no se encuentran ( 0 al menos no de manera tan acentuada) en la mayoría de asociados 3 :

"Tengo el bachillerato, y después había hecho dos años de formación profesional para luego trabajar como profesora de francés en los colegios, bueno en los institutos, en los institutos de Marruecos. Y ahora estoy estudiando aquí, en la Universidad de, de España, UNED. [...] Yo cuando sabía que iba a venir, me apunté en Marruecos y estudié durante seis meses, antes de venir, pero antes de tener la idea de venir nunca sabía el español, no. Cuando ya tenía decidido que vendré, mm, estudié durante seis meses, allí, o casi un año, un año. [...] Claro, porque yo allí estaba ejerciendo de, de profesora y aquí ya no es lo mismo, porque no equivalen ni los títulos ni nada" (ASEMT09).

\footnotetext{
${ }^{3}$ Las grabaciones y transcripciones estarán a disposición de los investigadores que las soliciten.
} 
"En el 71 me nombraron coordinador, presidente, coordinador de la UNEM (Unión Nacional de Estudiantes Marroquíes). [...] Organicé entonces también un encierro en la embajada y me quitaron la beca. [...] Había movimiento estudiantil, organizaciones políticas españolas, y me metí... Bueno, primero colaboraba con el partido comunista, luego con la liga comunista, y después pasé al Crap [...] Como además en Marruecos pertenecía a la organización llaldam, organización marxista leninista marroquí... Pues nada, en la actividad política y estudiantil. Pasé una época psicológica bastante... Estaba en manos de psiquiatras, o sea, era un conflicto interno bastante fuerte" ("Además pasé una época personalmente bastante dura, ¿no? Porque el cambio en la mentalidad de esta, creyente religiosa, a pasar a la parte ya atea radical, o sea...") Con organizaciones políticas, he colaborado con varias. [...] La lucha política y obrera, porque aquí, pues con los políticos, entonces, era ya, desde hacer pintadas, a montar manifestaciones, pasar toda la noche haciendo... fotocopias con ciclostil [...] Participaba en Comisiones (Obreras), yo me afilié al principio de nacer Comisiones en Valencia" (AMAHV09I).

Entre los discursos de los propios informantes se vislumbra la importancia de la socialización primaria, donde el contexto familiar va a ser fundamental:

"Bueno... yo, cuando tenía 6 años, mi padre me ha llevado a una manifestación de Primero de Mayo de trabajadores. Eso a los 6 años. Después me inscribí en organizaciones no gubernamentales $y$, después, también he participado en un partido político" (AMAHLL10).

"[...] porque mi madre es maestra y mi padre era... uh, tenía sus negocios, ¿sabes? Y yo he tenido de verdad una juventud muy bien, porque he nacido en una familia muy bien" (ASEMT09).

Incluso en esa importancia de la socialización y el aprendizaje social, del contexto familiar, vemos cómo el líder se va formando:

"Vivía en Girona, pero como mi hermano estaba de vicepresidente de la de Barcelona, estaba muy bien" (ASEMT09).

De hecho, entre los interlocutores entrevistados destacan personas cuyas familias son culturalmente inquietas, con predisposición a los estudios. La mayoría tienen una cierta experiencia asociativa, previa y precoz (ya en la adolescencia) en los países de origen.

En ocasiones tienen lugar ciertos procesos de pseudorresocialización, o al menos, fracturas importantes en el desarrollo vital como son las fracturas identitarias entre la religión (creyente practicante) y la propia nacionalidad, en un marco de identidad escindida: 
"Cuando terminé el bac, porque en mi pueblo, en Kazarquevil, no había bac, así que lo hice en Tetuán, hice el bac, y allí pues me metí de imam, además como sabía el Corán...[...] No había imam en el internado, pues yo hice de imam casi durante dos años y pico, hasta que ya... Además pasé una época personalmente bastante dura, ¿no? Porque el cambio en la mentalidad de ésta, creyente religiosa, a pasar a la parte ya atea radical, o sea..." (AMAHV09I).

"Ahora ya es un cambio total si bajo yo a Argelia saben que no soy argelino, saben que soy argelino de cara pero la mente ya no es argelina, es otra completamente, aunque soy musulmán practico, rezo... pero se nota un montón, también se nota en mis hijos" (AARHN10).

Se dan también situaciones de ambición educativa, de motivación de logro:

"Aquí vivía enfrente de la escuela oficial de idiomas como tengo base de francés y base de inglés, yo quería estudiar. Porque yo he venido y me encuentro entre cuatro muros sola, al menos estudiar. $Y$ he ido a apuntarme a la escuela de idiomas y me han dificultado las cosas, dice que no que tienes que...., yo tengo el bachillerato, pero es diferente que aquí, la secundaria, son tres años, no son dos como aquí" (AARMN10).

"[...] por el idioma, porque yo ya había estudiado francés y me sentía bien. Pero lo que faltaba era que las condiciones de vida eran más difíciles y no se podía seguir estudiando y costaba más, y me dijo: "bueno, si no puedo, me voy a España" [...] nadie valora lo que tú eras antes, ¿me explico?" (ABFMG10).

Las trayectorias vitales tienen estas constantes que hemos ido indicando, con muchas similitudes en lo que se refiere al género, prácticamente con pocas diferencias entre las masculinas y femeninas. Algunas consideraciones al respecto pueden ser la mayor sensibilidad por los temas de la mujer y en algunos casos un feminismo militante, ante una reconocida y mayoritaria visión patriarcal.

Así, hay una cierta resignación (o impotencia) ante el poder de los hombres, que se sortea de alguna manera a través de la propia cooperación entre las mujeres que lleva a la creación de asociaciones integradas únicamente por mujeres, y/o a reivindicaciones embrionarias al menos en el plano discursivo:

"Que a lo mejor el marido no la dejaba participar en una asociación, ir a cualquier hora, no sé qué, porque hay hombres, pero al estar... Es una asociación solo de mujeres, digamos que los hombres como que se están un poco más..., más tranquilos" (AMAMB09).

"Y yo con toda la creencia cultural de allí, que los hombres hacen presiones a las mujeres y no les dejan el espacio para vivir. Siempre que yo le he comentado a mi marido que quiero estudiar idiomas, siempre dice que no se puede porque ya ha comenzado 
el año, y yo he dicho: "No, no, no puede ser eso", esto es que él no quiere. Yo siempre cogía el ejemplo de los hombres de allí, del machismo de allí. El hombre siempre quiere que me quede en casa. Y yo pasé un mal momento" (AMAMT10II).

"En África están acostumbrados, porque en África los hombres no se asocian, es aquí que se asocian. Y nosotras pensábamos, cuántos hombres que se asocian aquí, ¿dónde están las mujeres? Allí no hacen nada, no encuentras hombres, todo el tema social, del cambio climático, son mujeres. ¿Por qué esto? Esto fue uno de los motivos que nos motivaron para luchar" (ABFMG10).

También se dan rechazos sin ambages del rol de ama de casa; en la cita de una informante se remarca dicho rechazo de manera explícita y la fuerza de dicha oposición está también remachada con una triple negación (por si pudiera quedar alguna duda):

(Te mueves entre los dos mundos) "Sí, porque la experiencia la he traído de mi país. Cuando he venido aquí, no me ha gustado ser solo ama de casa, no, no me ha gustado" (AARMN10).

Se dan dificultades claras para superar la segregación de género (en una mezcolanza de cuestiones sociales, culturales, religiosas y políticas), siendo preponderante el marcador de la tradición (religiosa y cultural en general):

"[...] las mujeres son muy conservadoras [...] si quieres que las mujeres se junten a la primera no lo admiten, les cuesta, es una pared muy gorda que no puede romperse de un golpe [...] no es una integración sociedad-emigrantes, no, hombre-mujer en el mismo lugar, es la cultura la que lo marca, la tradición lo que marca, la religión lo que marca, pegarte contra todo esto es como pegarte contra la pared" (AARHN10).

De todas maneras, también tenemos ejemplos de incorporación femenina, en una comisión de mujeres dentro de la asociación:

"[...] cuando hacíamos una fiesta, hacíamos comida, entonces ahí ellas venían y participaban. Antes, muy pocas mujeres participaban de la fiesta. Y había música, conseguimos que salieran. Con la sensibilización y la confianza que inspirábamos pues iban participando" (AMAHG10I).

Conjuntamente con la cuestión de género nos encontramos con la cuestión generacional, ya que entre los grupos culturales subsaharianos, principalmente, lo postfigurativo (Mead 1971: 33 y ss.) tiene un peso específico; los mayores enseñan y orientan claramente a los más jóvenes:

"La Asociación empezó porque a un buen señor nuestro, que es una persona mayor, vio que aquí, en Castellón, había muchísimos senegaleses que se encontraban a veces 
con problemas [...] y nos pidió si pudiéramos fundar una asociación [...] El primer presidente es un hombre mayor que ya está jubilado, está en Senegal. Ya no viene y cuando hicimos la reforma de la junta directiva y cambiar un poco los estatutos, pues me pusieron de presidente porque yo anteriormente era el secretario, y me pusieron de presidente [...] Yo por mi parte como presidente tengo mis asesores, que son gente mayor [...] Son analfabetos, pero llevan mucho tiempo aquí y son gente mayor que ya saben muchas cosas [...] Son gente analfabeta, pero con la cabeza muy cuadrada (sic) [...] mayores, edad de jubilar, sesenta o más, o cerca de sesenta, cincuenta y pico, y mayores también [...] En Senegal, no sé si lo sabías, pero es un sistema casi patriarcal. Alli el hombre mayor es el que..., casi es lo que suele decir, se suele hacer... Es la autoridad, por esto dicen en África: cuando muere una persona mayor, se ha cerrao una biblioteca. Y eso es que son analfabetos pero saben muchas cosas" (ASEHV09).

\section{Estilos de liderazgo}

Se muestran estilos de liderazgo que dependen de todos estos factores que hemos ido mencionando, del género, del componente generacional, del grupo cultural de pertenencia, etc. En este sentido, destacamos estilos de liderazgo fuertes, liderazgos transaccionales, en la línea del liderazgo carismático weberiano y/o un cierto "despotismo ilustrado", que se concreta y se ilustra en algún caso a través de la distancia entre la junta y el resto de los asociados ("clientes"):

"Nosotros no tenemos asociados marcados como socios, lo que tenemos son actividades, son cinco personas que van creando actividades para todos, pero cuando tengamos que cambiar la dirección, no sé como lo vamos a hacer pero casi seguro que lo hacemos de esta forma, cuando queramos cambiar los directivos nos juntamos los cinco de la junta directiva y lo transmitimos aquí dentro del centro" (AARHN10).

"[...] tienes que repetir muchas cosas porque la participación es difícil, gente que trabaja muchas horas, gente que se queja por problemas de racismo" (AMAHG10I).

Sin embargo, también tenemos ejemplos de otros estilos de liderazgo más participativos con iniciativas corales, no es un liderazgo únicamente "personalizado/carismático", ya que está reforzado con institucionalización.

"Los fines de semana, a veces si voy de mañana, tengo la tarde libre, así nos podemos ver y allí también empecé, con las chicas que había allí, a formar unas asociaciones de mujeres, y así van poco a poco más grandes. Ahora yo he venido a Montblanc, pero todavía sigue funcionando lo que dejé allí con ellos" (ASEMT09).

Este tipo de liderazgo, más del tipo inspirador o persuasivo, implica tener iniciativas, implicación social, participación en la escuela (por ejemplo), en definitiva abrir caminos de socialización, de integración: 
"Yo fui a hablar con la directora, y le dije que a mi hija le preguntaban, una amiga suya, si en Senegal vivimos con los animales salvajes y eso, y fui a hablar con ella y le decía ¿por qué no nos invitan a hacer una charla sobre Senegal? Y los niños, porque una niña que lo pregunta a mi hija no es mala niña, lo pregunta porque no sabe, y ella está muy contenta y me ofreció eso, y fui yo la primera vez, hice una charla, han grabao, han hecho fotos, y los niños tenían cada uno un papel con una pregunta y contestaba todas las preguntas, y conocieron así el Senegal. Ellos se animaron. Después invitaron a otra de Rumanía, una de China, otra del Nepal [...] me llamaron para ver si les podía ayudar para ir a hacer lo del rey negro, y también un chico de aquí, fui con él y le presenté a la directora, y es el que fue a hacer de rey negro para los niños, para que veas que ellos antes no tenían esta idea" (ASEMT09).

En todo caso, la tensión entre autoridad y poder existe en los liderazgos de las asociaciones. Dicha tensión se manifiesta con ambivalencia, como un antagonismo simmeliano, que no deja de ser la doble cara de la misma moneda; se busca y se quiere la auctoritas, pero no se deja de ejercer el poder si es necesario. En este caso, la opción por un liderazgo de tipo transaccional con toques incluso de cierto maquiavelismo aparece muy nítida:

"Yo, nunca... Es que una de las cosas que siempre he odiado es ser presidente de algo. En todo caso, coordinador. Me gusta estar siempre a la sombra, ¿no? Eh, sí, formé parte de una comisión. Me nombraron... nombramos un presidente. Me querían nombrar a mí, yo dije que no, pero nombraron un presidente y yo era un vocal, pero vocal a su vez portavoz, y sigo hasta ahora de portavoz [...] Querían traer el velo marroquí. Marruecos no es un país laico, es un país religioso. Por tanto ese modelo marroquí no me gustaba. Entonces, hice un golpe de estado interno. Eh, un pequeño golpe de estado. Nos reunimos algunos que estábamos en contra, buscamos otros y es cuando vimos a Amir, ¿eh? O sea, Amir vino ya, las compañeras también. Eh, una vino, vino Nadia... [...] O sea, en la próxima reunión, los quitamos de en medio, o sea, la... la renovamos, la junta directiva, y hemos empezado la nueva junta directiva, laica, con participación activa de la mujer. Empezamos a hacer proyectos para mujeres, ya empezamos a actuar como una asociación de inmigrantes, y con carácter, no de trabajo, sino también principalmente reivindicativo, que era el objetivo principal e inicial de la asociación, por eso yo me entré alli" (AMAHV09I).

En muchas ocasiones predomina un discurso reivindicativo tanto en relación con la integración de los inmigrantes como con el papel subordinado de la mujer hacia el hombre e incluso también la subordinación étnica de algunas minorías como la Amazigh (en este caso predomina también sobre el propio tema migratorio y feminista):

"Yo y las otras asociaciones de marroquíes, cojamos por ejemplo Samira. Samira nunca aceptará (hacer cosas conjuntamente entre asociaciones); es una chica que 
es de origen de mi pueblo, Samira y su hermana [...] Pero nunca aceptará ir a alguna cosa que sea amazigh. [...] A mí esto no me trae ningún problema, yo estoy lista para colaborar con las otras asociaciones. Pero la mayoría, cuando se entiende que es de amazighs, "Ah, estos que quieren destruir Marruecos, estos que quieren la autonomía, estos que no sé qué..." (AMAMT10II).

En la línea reivindicativa se halla la lucha contra los estereotipos, contra los prejuicios de la población autóctona y también de los propios inmigrantes. Esta última consideración es digna de resaltar ya que en más de una ocasión se establece una relación directa entre reivindicación y la propia defensa del grupo, olvidando la importancia de las interrelaciones sociales y el papel del "nosotros" conjuntamente con el del (no necesariamente "en contra del") "ellos":

"Lo que muestran en la tele, que todos vienen en pateras, que somos personas que no tienen ni educación ni clase social, que nos ponen a todos en el mismo saco, sin saber quién es quién, por ejemplo. Entonces esta percepción crea malestar, frustraciones, pensar que todos somos iguales, que África es muy grande, pero África también tiene el lado positivo, no todo es negativo como lo que muestran por la tele. Y esto hace daño. Sale siempre pobreza, guerra... pero hay el lado positivo que nunca sale, aunque ahora hay documentales positivos, no como antes [...] También haremos donaciones de sangre para quitar este mito que hay sobre la donación de sangre con las africanas, porque tenemos la idea de que cuando te sacan sangre, te quedas sin sangre. $Y$ entonces tenemos una actividad planificada para poder mostrarles a las mujeres que no se quedan sin sangre y quitar este mito" (ABFMG10).

Hay que destacar también como entre algunos de nuestros informantes se da un discurso comprometido y proactivo, buen ejemplo este del aprendizaje del liderazgo como confluencia entre factores situacionales como el origen familiar, en especial la potente figura materna y/o la experiencia previa en el país de origen, así como variables personales en la línea de la motivación de logro, la capacidad de compromiso, la vocación altruista, etc.

"Porque la sociedad no los aceptan y aún les siguen llamando inmigrantes a pesar de haber nacido aquí [...] yo me estoy formando para hacer la página web, a distancia, cada noche. Porque no podemos esperar a que todo nos ayuden sino que hay que espabilarse y aprender a hacer [...]. Porque mi madre ha dicho siempre que tenemos que demostrar a la sociedad lo que valéis, aunque tengamos 10 hijos. Y que una mujer no para de luchar. Y siempre que me acuerdo de esto, me da más fuerza" (ABFMG10). 
El liderazgo tiene mucho que ver también con la gratuidad, con el espíritu y la labor de voluntariado:

"Yo estaba colaborando con una, no es una asociación, es la organización de derechos humanos, eh, estuve colaborando un tiempo antes de venir aquí a España, es la única donde estuve allí [...] Todos son voluntarios, son mujeres que quieren participar, que quieren hacer actividades [...] Se fue la secretaria y yo empezó así, me puse en el sitio de la secretaria, ayudando un poco, luego $\mathrm{mmm}$, se fue la vicepresidenta, y después de las elecciones, me eligieron como vicepresidenta, y en el último era que la que era la presidenta, por motivos personales no podía, se fue de..., del pueblo, y por motivos personales no podía seguir con el puesto [...] y por voto de las socias y todo, $\mathrm{mmm}$, he sido elegida" (AMAMB09).

"No te pagan, y tienes que dejar... Muchas veces levantarse de noche, te llama la policía: aquí tenemos un senegalés, ¿puedes venir a hacer de intérprete? Dejas tus sueños y te levantas, y si te tienes que levantar a las seis de la mañana para ir a trabajar..." (ASEHV09).

"A mí la Asociación, mensualmente, me cuesta entre 90 y 125 euros. Fíjese, mensualmente. Yo, a mí, nos cuesta de nuestro bolsillo, pero bueno, la tenemos que mantener... Por eso te digo que estoy hasta los huevos ya, jaja. Quiero dejarlo ya, jaja. Porque ya es... Me estoy haciendo viejo. A ver los jóvenes si quieren [...] no he parado toda la vida ¿Qué más puedo aportar ya a esta...? No he parao, hay que parar un poco [...] Nosotros tenemos nuestro trabajo desde las nueve de la mañana hasta las siete de la tarde, pues dime tú cuándo... El fin de semana que quiere descansar... a la Asociación, pues, hay que cortar un poquito [...] Porque cualquier actividad, cualquier proyecto, necesita dinero, y no tenemos. Eh, lo que tenemos es nuestra fuerza de voluntad, nuestro sacrificio, nuestro tiempo, que lo llevamos dedicando, y ya te digo [...] No, aquí no somos voluntaristas así porque sí. No, queremos... tenemos unos principios que queremos conseguir. Estamos... llevamos 10 años luchando, los hemos conseguido... yo creo, por mi parte al menos, yo creo que es demasiado [...] o sea, yo quiero retirarme ya" (AMAHV09I).

La capacidad de diálogo y negociación, elementos constitutivos del liderazgo transformacional o inspirador [según la denominación de Bass (1998) o de Nye (2011)], son fundamentales en la conducción de las asociaciones:

"Se da resultado cuando... se negocia con calma, con tranquilidad, hablar con la gente, con todas las partes [...] cuando llegamos a un camino cerrado, bueno, escogemos los medios de comunicación para buscar apoyo" (AMAHLL10). 


\section{CONCLUSIONES}

Después de muchas décadas de investigación, lo cierto es que el fenómeno del liderazgo sigue siendo un territorio de las ciencias sociales en el que nuestro conocimiento del tema aún es parcial y fragmentario. Debemos reconocer que nuestro esfuerzo de revisión bibliográfica no ha obtenido resultados relevantes respecto a mejorar la capacidad analítica de los resultados empíricos de nuestro estudio. Tal vez la premisa de los funcionalistas de la continuidad estructural entre los sistemas sociales, de los microgrupos a las sociedades complejas, fuera excesivamente ambiciosa. En el caso concreto del liderazgo parece obvio que entre los estudios de laboratorio y las investigaciones en la vida real sobre organizaciones o comunidades concretas existen notables diferencias. Tal vez el problema sea conceptual: ¿se puede usar el término 'liderazgo' para definir, entre otras, funciones de influencia y dirección en ámbitos sociales tan radicalmente heterogéneos?

En segundo lugar, el análisis comparativo entre las asociaciones de inmigrantes africanos, masculinas y femeninas, indica que el asociacionismo de estas últimas es minoritario (un diez por ciento del total) y reciente (su creación así como la mayoría de las afiliaciones se concentra en los últimos tres años). Que en ningún caso superen el centenar de asociadas y que, en general, las altas sean escasas e inferiores a las bajas completan un cuadro de desigualdades de género. Obviamente ello no es específico de la población de origen extranjero, pero no es menos cierto que alcanza entre ellos una dimensión muy explícita. No se han encontrado grandes diferencias entre ambos modelos asociativos en cuanto a intereses 0 actividades predominantes, pero en las asociaciones exclusivamente femeninas o con predominio de mujeres destaca el énfasis en la mediación intercultural, mientras que en las organizaciones masculinas destacan -aquí las diferencias son estadísticamente significativas_ la sensibilización externa y la inserción laboral. Una vez más estos resultados son concordantes con la bibliografía consultada (Juliano y Lurbe 2000; Sipi 2000) y confirman la hipótesis de la persistencia de importantes asimetrías de género.

En tercer lugar, de los datos procedentes del análisis de los discursos de nuestros informantes cuatro cuestiones nos parecen significativas:

1. La decisión metodológica de diferenciar entre liderazgo y dirección (Fiedler 1971; Covey 1996; Nye 2011) parece pertinente ya que nuestros sujetos manifiestan que, más allá de su posición en el organigrama asociativo, realizan una serie de roles grupales que van más allá de las funciones meramente jerárquicas o formales.

2. Los estilos de liderazgo, así como los roles desempeñados son tan diversos y cambiantes que rebasan las tipologías consultadas en la revisión bibliográfica. Por ejemplo, y basándonos en la teoría de la identidad social (Haslam 2004) respecto al ámbito endogrupal, construir la identidad asociativa ("inventar" el nombre, aglutinar al grupo, ofrecer no solo servicios sino apoyo emocional, 
luchar contra la ignorancia y prejuicios de los miembros) versus comunicar y reivindicar hacia fuera dicha identidad: funciones de ideólogo, publicista, "intelectual"... que combaten los prejuicios y estereotipos hacia el colectivo inmigrante.

3. Prácticamente la totalidad de los informantes remite a experiencias de socialización familiar, escolar o comunitaria (deportiva, cultural, sindical...) como procesos facilitadores del aprendizaje del liderazgo. Además suelen coincidir con una etapa temprana (adolescencia, primera juventud...) del ciclo vital. Predominan discursos que privilegian el esfuerzo, la actitud favorable a un permanente aprendizaje formativo, así como la motivación de logro.

4. Entre los varones jóvenes, especialmente de origen subsahariano, el camino hacia el liderazgo está claramente enmarcado en situaciones de enculturación postfigurativa (Mead 1971) ya que los mayores (los séniores) actúan frecuentemente como mentores. En el liderazgo femenino, dentro de un discurso de reivindicación femenina muy claro y directo, la figura de la madre parece ser crucial.

No obstante, no hemos sabido encontrar diferencias de género, por ejemplo de mayor inteligencia emocional entre las mujeres, entre los múltiples y variados estilos de conducción y dinamización de las asociaciones estudiadas. El aprendizaje temprano de responsabilidades, la motivación hacia la formación y un origen social relativamente acomodado parecen estar igualmente repartidos entre las diez personas analizadas (aunque debemos admitir que la pequeñez de la muestra nos obliga a ser cautos a la hora de extrapolar estos resultados).

En resumen, el presente artículo aporta como elementos de reflexión el cuestionamiento de ciertos prejuicios y estereotipos no por infundados menos extendidos. Por una parte, frente al tópico de las mujeres inmigrantes africanas como personas sumisas, ignorantes y débiles, los datos ofrecen perfiles de sujetos con capacidad para el liderazgo. Pero por otra, frente a la esencialización de un liderazgo femenino fundamentado en capacidades innatas de las mujeres, nuestros resultados sugieren que el liderazgo responde, tanto en los varones como en las mujeres, a unos procesos de socialización específicos, articulando las características personales, aptitudes pero también actitudes, con una preparación y un contexto, mentores y grupos de referencia, favorecedores del proceso.

\section{REFERENCIAS BibLIOGRÁfICAS}

Bales, R. F. 1950. "A set of categories for the analysis of small group interaction." American Sociological Review 15:257-263.

Barberà, E., M. Sarrio y A. Ramos. 2000. Mujeres directivas: promoción profesional en España y Reino Unido. Colección Quaderns Feministes 2. Valencia: Institut Universitari d'Estudis de la Dona. 
Bass, B. M. y B. J. Avolio. 1990. Transformational leadership development: Manual for de Multifactor leadership Questionnaire. Palo Alto: Consulting Psychologists Press.

Bass, B. M. y B. J. Avolio. 1994. "Shatter the Glass Ceiling: Women May Make Better Managers". Human Resource Management 33:549-560.

Bass, B. M. 1998. Transformational leadership: Industrial, military, and educational impact. Mahwah, $\mathrm{NJ}$ : Erlbaum.

Beauvoir, S. 1949. El segundo sexo. Buenos Aires: Siglo Veinte.

Blake, R. y J. Mouton. 1964. The managerial grid: key orientations for achieving production through people. Houston, Texas: Gulf.

Cantó, N., A. Castiñeira y A. Font. 2009. Les fonts del lideratge social. Barcelona: Fundación Jaume Bofill.

Chinchilla, N. y C. León. 2004. La ambición femenina. Cómo reconciliar trabajo y familia. Madrid: Santillana.

Covey, S. R. 1996. "Los tres papeles que desempeña el líder del nuevo paradigma”. Pp. 177-189 en El líder del futuro, editado por F. Hesselben, M. Goldsmith y R. Beckhard. Bilbao: Deusto, The Drucker Foundation, Jossey-Bass Inc. Publishers.

Druskat, V. U. 1994. "Gender and leadership style: transformational and transactional leaderships in the Roman Catholic Church". Leaderships Quarterly 5:99-119.

Eagly, A. y L. Carli. 2003. "The female leadership advantage: an evaluation of the evidence". The Leadership Quarterly 14:807-834.

Fiedler, F. E. 1974. "El estudio del liderazgo. El modelo de la contingencia". Pp. 911-955 en Teoría e investigación en la Psicología Social actual, editado por J. R. Torregrosa. Madrid: M. I.O.P.

Fisher, H. 2000. El primer sexo. Las capacidades innatas de las mujeres y cómo están cambiando el mundo. Madrid: Grupo Santillana.

Gardner, H. 1998. Mentes líderes. Una anatomía del liderazgo. Madrid: Paidós.

Gibb, C. A. 1969. "Leadership". Pp. 270 en The Handbook of Social Psychology, edited by G. Lindzey and E. Aronson. Oxford: Oxford University Press.

Giddens, A. 1989. Sociology. Cambridge: Polity Press.

Haslam, S. A. 2004. "Leadership". Pp. 566-568 in The Social Science Encyclopedia, vol. II, edited by A. Kuper. London: Routledge.

Hollander, E. P. y J. W. Julian. 1974. "Tendencias actuales en el análisis de los procesos de liderazgo". Pp. 957-974 en Teoría e investigación en la Psicología Social actual, editado por J. R. Torregrosa. Madrid: Instituto de la Opinión Pública.

Homans, G. [1950] 1963. El grupo Humano. Buenos Aires: EUDEBA.

Joly, D. 1987. "Associations among the Pakistani Population in Britain". Pp. 62-85 en Immigrants Associations in Europe, editado por J. Rex, D. Joly y C. Wilpert. Gower: Alderhot.

Juliano, D. y K. Lurbe. 2000. "Mujeres estructuralmente viajeras: estereotipos y estrategias". Papers 60:381-389. 
Martínez, A. 2011. "Liderazgo, género e identidad étnica en Ecuador". Comunidad Virtual de Gobernabilidad - Comunidad Virtual de Desarrollo Humano e Institucional. Consultado 22 de Noviembre 2011 (http://www.gobernabilidad.cl/modules.php?name=News\&file=article\&sid=1396).

Mead, M. 1971. Cultura y compromiso. Buenos Aires: Granica.

Peters, T. 2005. La esencia del liderazgo. Madrid: Pearson.

Puigvert, L. y B. Muñoz. 2012. "Estudios de género. Barreras y aportaciones al debate teórico internacional desde las voces de las 'otras mujeres'”. Géneros. Multidisciplinary Journal of Gender Studies $1: 4-27$

Pujadas, J. J. 1992. El método biográfico: el uso de las historias de vida. Madrid: Centro de Investigaciones Sociológicas (CIS).

Nye, J. C. 2011. Las cualidades del líder. Barcelona: Paidós.

Ramos, A., M. Sarrio, E. Barberá y C. Candela. 2002. "Mujeres directivas y demandas organizacionales". Revista de Psicología Social 17:183-192.

Ruiz Olabuénaga, I. 2003. Metodología de la investigación cualitativa. Bilbao: Universidad de Deusto.

Sipi, R. 2000. "Las asociaciones de mujeres iagentes de integración social?". Papers 60:355-364.

Szepanti, J. 1978. "El método biográfico". Papers 10:229-256.

Weber, M. [1922] 1984. Economía y Sociedad. México: Fondo de Cultura Económica.

Fidel Molina Luque es Catedrático de Sociología de la Universidad de Lleida. Decano de la Facultad de Ciencias de la Educación (1998-2001 y 2001-2004) y, actualmente, Director del Instituto de Ciencias de la Educación-Centro de Formación Continua (ICE-CFC). Ha publicado diferentes artículos, libros y capítulos de libros sobre temas de Sociología de la Educación y Educación Intercultural, sobre Conflictología (Negociación, Mediación y Resolución de Conflictos) y también sobre cuestiones de Ocio y Deporte, y sobre Gestión y Formación de Recursos Humanos. Impulsor y coordinador del GESEC (Grupo de Estudios Sociedad, Educación y Cultura), inscrito en el CEJEM, y de la RINEIB (Red Internacional de Investigación en Educación Intercultural y Educación Intercultural Bilingüe). Ha recibido el premio (colectivo) "Grundtvig Award 2005 " al mejor proyecto europeo de Educación de Adultos ("Telling Europe"). Invitado por el FRA (Fonamental Rights Agency) de la Unión Europea, como asesor en Metodología de Investigación (Investigación-Acción Participativa) para un proyecto de integración del pueblo gitano en Europa (Viena, 2012).

LuIS SAmper Rasero es actualmente profesor emérito del Departamento de Geografía y Sociología de la Universidad de Lleida, y dirige el GRER (Grup de Recerca d'Escola Rural), inscrito en el IRIS de la citada universidad. Se doctoró en Filosofía y Letras en la Universidad de Barcelona (1981), con una tesis sobre Socialización diferencial de Género, dirigida por Claudi Esteva. Diplomado en Sociología (ICS e IEP) y Pedagogía Terapéutica (UAB). Como CEU ha impartido cursos de Sociología de la educación y de la familia en la Facultad de Educación de la Universidad de Lleida (1979-2010). 
Dolors Mayoral Arque es Profesora Agregada de Sociología de la Facultad de Ciencias de la Educación de Lleida y Coordinadora Adjunta al Rector para la Innovación Docente. Ha formado parte del proyecto Asociacionismo e inmigración africana: funciones latentes y manifiestas. Dentro de esta línea de trabajo ha publicado Culturas en interacción: la vida cotidiana (2009) y el Ágora compartida: Democracia y asociacionismo de inmigrantes (2011). También el artículo "Islamofobia o currículo nulo. La representación del Islam, las culturas musulmanas y los inmigrantes musulmanes en los libros de texto de Cataluña".

RECIBIDO: $24 / 09 / 2012$

ACEPTADO: $27 / 03 / 2012$

Publicado on-line: 13/06/2013 